\title{
Primary Gall Bladder Carcinoma:A one year prospective study at a tertiary care center.
}

\author{
Zubaida Rasool M.D., 'Nuzhat Samoon M.D., ${ }^{2}$ Nazia Bhat M.D., ${ }^{3}$ Huzaifa Nazier M.D., \\ Kanika Gupta M.B. ${ }^{5}$
}

'Additional Prof., ${ }^{2,3,4}$ Senior Residents, ${ }^{5}$ PG Scholar Department of Pathology SKIMS, Soura

\section{A B S TRACT}

Background: Gallbladder carcinoma is not an uncommon clinical entity in the Indian scenario, unlike western countries. It is predominantly a disease of females.Association between gallstones and Gallbladder carcinoma is strong.Itscarcinogenesis follows a progression through a metaplasia-dysplasia-carcinoma sequence.An early diagnosis is essential as this malignancy progresses silently with a late diagnosis, often proving fatal Therefore, every gallbladder should be subjected to routine histopathological examination because with identification of an early gallbladder carcinoma a curative resection may be possible, and these patients have a good survival rate.

Methods: This was a prospective study done on 22 cases of gall bladder carcinomas over a period of 1year from 1st November 2017 to 1 st November 2018.

Results: Present study showed that gallbladder cancer is predominantly a disease of elderly females. In present study, abdominal pain 18 cases $(81.81 \%)$ followed by anorexia 15 cases $(68.18 \%)$ and dyspepsia 14 cases $(63.63 \%)$ was the most common presenting symptom present .Cholelithiasis was found in only $5(22.72 \%)$ of our patients. Adenocarcinoma was the most common histopatholgic variant found in 20 cases $(90.90 \%)$ followed by squamous cell carcinoma 2 cases (9.09\%).

Conclusions: Every gallbladder should be subjected to routine histopathological examination because with early stage disease a curative resection may be possible, and these patients have a good long-term survival. JMS 2018: 21 (2):91-94

Keywords: Carcinoma gall bladder, Gall stone, abdominal pain,Adenocarcinoma.

\section{INTRODUCTION}

Carcinoma of the gallbladder is a rare malignancy accounting for approximately 7,100 new cases and 3,500 deaths per annum in the US. It is the most common biliary tract malignancy and the fifth most frequent gastrointestinal malignancy ${ }^{[1]}$. In India, the prevalence of GBC varies on geographical distribution whereas it is higher in North India compared to South India ${ }^{[2]}$. In an analysis of various cancers from Kashmir, gall bladder cancer was found to have a percentage prevalence of $2.2 \%$ with a female preponderance ${ }^{[3] .}$

Gallbladder carcinoma is two to six times more common in women than men $^{[4,5] .}$ Incidence increases with age and more than $75 \%$ of patients with this malignancy are older than 65 years $^{[6]}$

The aetiology of gall bladder cancer has been a source of

\section{Correspondence}

Dr. Nazia Bhat

Senior Resident, Department of Pathology SKIMS, Srinagar Email:bhatnazia2@gmail.com
speculation.The incidence of gall bladder cancer parallels the prevalence of gall stone disease; large and long standing gall stones being associated with the higher risk of gall bladder cancer ${ }^{[7,8]}$. The risk of gall bladder cancer in patients with gall stones has been reported to have increased 4-7 times $^{[6]}$. Increasing stone size augments the risk of gallbladder cancer; stones more than $3 \mathrm{~cm}$ carry a tenfold increased risk when compared with smaller stones ${ }^{[9]}$. Its clinical presentation is nonspecific and the majority of patients have advanced disease at presentation. The overall prognosis has remained dismal with a 5-year survival of $10 \%$ due to the late detection of the disease while the median survival for patients with suspected cancers is 9.2 months, and for those with incidentally diagnosed cancers, 26.5 months ${ }^{[1,7]}$.The dismal prognosis, in part, relates to the gallbladder lacking a serosal layer adjacent to the liver, enabling hepatic invasion and metastatic progression. Improved imaging modalities are helping to diagnose patients at an earlier stage. The last decade has witnessed improved outcomes as aggressive surgical management and preoperative adjuvant therapy has helped prolong survival in patients with gallbladder cancer ${ }^{[10]}$. 


\section{METHODS}

This was a prospective study carried out in the Department of Pathology,Sher-i-Kashmir Institute of Medical Sciences, Soura over a period of 1 year from 1stNovember 2017 tolst November 2018. A total of about 480 cholecystectomies were received during this period.Of these, 15 cases proved to be malignant on histopathology and these were included in our study. 3 review biopsies and 4 usg guided biopsies were also included in the study. Therefore total number of malignant lesions in our study were 22. The age, sex, relevant clinical and radiological details were recorded for each case. . The specimen was processed as per standard procedure . $4-5 \mathrm{~m}$ thick sections were cut on microtome and stained by hematoxylin and eosin stain. The stained slides were studied in detail microscopically; and Immunohistochemistry was done wherever necessary.

\section{RESULTS}

A total of 22 patients with gall bladder carcinoma were observed during this 1 year period. Males constituted 4 patients(18.18\%) and females constituted 18 patients(81.81\%).Male to female ratio was $1: 5$.The age of patients ranged from 39 years to 80 years. (mean of 56.31).The peak age of presentation was the fifth decade of life.

Most common abdominal symptom was abdominal pain in about 18 patients( $81.81 \%)$ followed by anorexia in 15 patients(68.18\%) and Dyspepsia in 14 patients(63.63\%) (Table1)

Table1: Clinical presentation of patients

\begin{tabular}{|l|l|l|}
\hline SYMPTOMS & $\begin{array}{l}\text { NO OF } \\
\text { CASES }\end{array}$ & PERCENTAGE \\
\hline Abdominal pain & 18 & $81.81 \%$ \\
\hline Anorexia & 15 & $68.18 \%$ \\
\hline Dyspepsia & 14 & $63.63 \%$ \\
\hline Jaundice & 2 & $9.09 \%$ \\
\hline Weight loss & 14 & $63.63 \%$ \\
\hline
\end{tabular}

Cholelithiasis was found in only $5(22.72 \%)$ of our patients. Gross morphology was studied in 15 patients. Tumor configuration was polypoidal in 7 cases $(46.66 \%)$ followed by infiltrative lesion in 6 cases $(40 \%)$ and gall bladder wall thickening in 2 cases9(13.33\%).Majority of lesions were found in the fundus of gall bladder 6 cases $(40 \%)$ followed by 5 cases $(33.33 \%)$ in body of gall bladder. In two cases lesion was found in neck of the gall bladder and whole body(13.33\%). Table 2

Table2: Gross Morphology in 15 patients

\begin{tabular}{|l|l|l|l|}
\hline Site of lesion & $\begin{array}{l}\text { Tumor } \\
\text { configuration }\end{array}$ & $\begin{array}{l}\text { No of } \\
\text { patients }\end{array}$ & Percentage \\
\hline Fundus /body/Neck & polypoidal & 7 & $46.66 \%$ \\
\hline Fundus or body & infiltrative & 4 & $26.66 \%$ \\
\hline Whole GB & Infiltrative & 2 & $13.33 \%$ \\
\hline GB wall thickening & & 2 & $13.33 \%$ \\
\hline Total & & 15 & $100 \%$ \\
\hline
\end{tabular}

On histopathopathology adenocarcinoma wasthe most common histopatholgic variant found in 20 cases $(90.90 \%)$ followed by squamous cell carcinoma 2 cases $(9.09 \%)$. Table 3

Table 3 : Histopathological findings in surgical specimens/biopsies

\begin{tabular}{|l|l|l|}
\hline Tumor Type & No of Cases & Percentage \\
\hline $\begin{array}{l}\text { Well differentiated } \\
\text { adenocarcinoma }\end{array}$ & 7 & $31.81 \%$ \\
\hline $\begin{array}{l}\text { Moderately } \\
\text { differentiated } \\
\text { adenocarcinoma }\end{array}$ & 9 & $40.90 \%$ \\
\hline $\begin{array}{l}\text { Poorly differentiated } \\
\text { adenocarcinoma }\end{array}$ & 2 & $9.09 \%$ \\
\hline $\begin{array}{l}\text { papillary } \\
\text { adenocarcinoma }\end{array}$ & 2 & $9.09 \%$ \\
\hline $\begin{array}{l}\text { squamous cell } \\
\text { Carcinoma }\end{array}$ & 2 & $9.09 \%$ \\
\hline TOTAL & 22 & $100 \%$ \\
\hline
\end{tabular}

Complete TNM staging was done in 15 cases only as 3 cases were review biopsies and 4 cases were usg guided biopsies.3 patients(20\%) had stage II disease, 5 (33.33\%)had stage IV disease. 7 patients $(46.66 \%)$ had stage III disease.Table4

Table4 : TNM Staging In 15 Patients

\begin{tabular}{|l|l|l|}
\hline STAGE & - & PERCENTAGE \\
\hline I & - & \\
\hline II & 3 & $20 \%$ \\
\hline III & 7 & $46.66 \%$ \\
\hline IV & 5 & $33.33 \%$ \\
\hline TOTAL & 15 & $100 \%$ \\
\hline
\end{tabular}

\section{DISCUSSION}

Maxmillan Destoll is credited with the first report of gall bladder carcinoma (GBC) on the basis of two autopsies in 
$1777^{[11]}$. Since then, the primary carcinoma of the gall bladder has remained a uniformly fatal neoplasm. The reasons being, a) its late presentation b) early spread by lymphatic, hematogenous and direct route c) high propensity to seed the peritoneal surfaces and d) lack of effective adjuvant therapy.

The present study revealed the mean age of the patients to be 56.31 years, with a range of 39-80 years and fifth decade as the peak age of presentation. Similar results were observed in other studies from India ${ }^{[12]}$. Results from present study showed that gallbladder cancer is predominantly a disease of elderly females; with an overall male to female ratio of $1: 5$. These results were consistent with the results of other studies where it was reported to be 1:3, 1:3 and 1:2.5 respectively ${ }^{[13]}$. In the present study, abdominal pain (81.81\%) followed by anorexia (68.18\%.)and dyspepsia $(63.63 \%)$ were the most common presenting features. Consistent results were reported in other studies ${ }^{[1,14]}$.

The etiology of gall bladder carcinoma is unknown but there is a clear worldwide association between chronic cholelithiasis and gall bladder carcinoma. The risk of developing cancer among patients of untreated cholelithiasis has been estimated to be $0.2-0.5 \%$ over a 20 year period. ${ }^{[14]}$ However in our study gall stones were found in 4 patients only. Other risk factors that increase the risk of gall bladder carcinoma include, a number of genetic, dietary factors, endo and exobiotics. Chronic inflammation and infection have been associated with the development of gall bladder carcinoma. ${ }^{[15]}$ Chronic inflammation cause DNA damage, which provokes repeated tissue proliferation and restoration attempts. This response involves the release of cytokines and growth factors and, thus, predisposes cells to oncogenic transformation. It has been found that higher intake of energy and carbohydrates possibly increase the risk of gall bladder carcinoma and adequate intake of fruits and vegetablesprobably reduce the risk of GBC as they contain potentially anticarcinogenic agent ${ }^{[16]}$.

Early carcinoma gallbladder may be detected on abdominal USG as a fixed polypoidal mass projecting in to the lumen of the gallbladder with absence of acoustic shadowing or as an asymmetric thickening of the gallbladder wall. Advanced tumours also show loss of interface between gallbladder and liver indicating tumour invasion, lymph node and hepatic metastases, dilated bile ducts and ascites. The diagnostic accuracy of CT scan at $60 \%$ is lower than that of USG. Its main advantage lies in showing tumour infiltration into adjacent viscera or vessels, lymph node and distant metastases. ${ }^{[1,14]}$

Pathologically GBC usually presents as a mass lesion. It may however form a localized wall thickening or a polypoidal growth. Approximately $60 \%$ of tumors originate in the fundus, $30 \%$ in the body and $10 \%$ in the neck(12).Our study had also comparable results.

Microscopically adenocarcinomas account for $90 \%$ of Gall bladder carcinomas and they may be well moderately or poorly differentiated. There are several histological variants of adenocarcinoma i.e. papillary, intestinal, mucinous, signet ring cell and clear cell. In our study we had 20 cases $(90 \%)$ of adenocarcinomas and 2 cases of squamous cell carcinoma $(10 \%)$.

Early stage gallbladder cancer can mimic cholecystitis, when presenting with biliary-type abdominal pain that warrants cholecystectomy. Such incidental gallbladder cancers are detected histologically after the fact in $0.3 \%-3 \%$ of laparoscopic cholecystectomies performed for cholelithiasis. In other cases, treatment options usually focus on curative resection, which can be compromised by the extent of tumor invasion. Indeed, primary tumor invasion (T) is the most important subset of the American Joint Committee on Cancer staging criteria; it determines the surgical approach ${ }^{[10]}$ Patients may require cholecystectomy with wedge resections involving segment $\mathrm{IVb}$ and $\mathrm{V}$ of the liver as well as portal lymphadenectomy ${ }^{[17]}$

Adjuvant chemotherapy and or radiotherapy for patients with Gall Bladder Carcinoma has not altered the dismal prognosis The overall outcome of this disease is dismal with the 5year survival rate being less than $5 \%$ with a median survival of 5 to 8 months ${ }^{[18]}$.

\section{CONCLUSION}

Gallbladder carcinoma although a rare entity in western countries is not an uncommon clinical entity in the Indian scenario. It is predominantly a disease of females. Therefore, a female especially in forties and fifties with a history of recent onset of constant pain in the right hypochondrium or change in the character of pain should be thoroughly investigated and evaluated. In spite of the advances made in the field of gallbladder imaging, the detection of carcinoma of the gallbladder in early stages remains low. Therefore, every gallbladder should be subjected to routine histopathological examination because with early stage disease a curative resection may be possible, and these patients have a good long-term survival. 


\section{Acknowledgements:}

Authors acknowledge the immense help received from the scholars whose articles are cited and included in references of this manuscript. The authors are also grateful to authors / editors / publishers of all those articles, journals and books from where the literature for this article has been reviewed and discussed

Financial support:

None

Conflict of interest: None

\section{REFERENCES}

1. Memon M A, Anwar S, Shiwani M H, MemonB.Gall bladder carcinoma: A retrospective analysis of twenty two years experience of a single teaching hospital. International semin in surgoncol 2005;2:6.

2. Tyagi BB, Manoharan N, Raina V. Risk factors for gallbladder cancer: A population based casecontrolstudy in Delhi. Ind $\mathrm{J}$ Med \&PaedOnco. 2008;29(1):16-26.

3. Rasool MT, Lone MM, Wani ML, Afroz F, Zaffar S, Mohib-ul-Haq M. Cancer in Kashmir, India: Burden and pattern of disease. J Can Res Ther 2012; 8: 242-6

4. Randi G, Franceschi S, La Vecchia C. Gallbladder cancer worldwide: geographical distribution and risk factors. Int J Cancer. 2006;118(7): 1591-1602. 8.

5. Konstantinidis IT, Deshpande V, Genevay M, et al. Trends in presentation and survival for gallbladder cancer during a period of more than 4 decades: a singleinstitution experience. Arch Surg. 2009;144(5): $441-447$

6. Vijay Kumar Tekam.A study the burden of carcinoma gall bladder in Hamidia hospital of Bhopal, Madhya Pradesh, India International Surgery Journal 2018 Feb;5(2):570-575

7 ShubhangiVinayakAgale, Sanjay Surase, Grace F. D'Costa, MukundTayade et al.Primary gall bladder carcinoma: a retrospectiveclinicopathological study at a tertiary care centre in mumbai. World Journal of Pharmaceutical and Medical Research 12017,3(2), 146151

8. Hamdani NH, Qadri SK, Aggarwalla R, Bhartia VK, Chaudhuri S, Debakshi S, Baig SJ, Pal NK.Clinicopathological study of gall bladder carcinoma with special reference to gallstones: our 8year experience from eastern India. Asian Pac J Cancer
Prev. 2012;13(11):5613-7

9. Lowenfels AB, Walker AM, Althaus DP, Townsend G, Domellöf L. Gallstone growth, size, and risk of gallbladder cancer: an interracial study. Int $\mathrm{J}$ Epidemiol. 1989;18(1):50-54.

10 Jayaraman S, JarnaginWR . Management of gallbladder cancer.GastroenterolClin North Am.2010; 39: $331-342$

11. DeStoll M: RationisMendendi, in Nosocomio Practicovendobonensi. Part I Lugduni Batavarum, Haak et Socios et A et J Honkoop1788 .

12. Piehler JM, Crichlow RW. Primary carcinoma of the gallbladder.SurgGynecol Obstet. 1978;147:929-42.

13. Roa JC, Tapia 0, Cakir A. Squamous cell and adenosquamous carcinomas of the gallbladder: clinicopathological analysis of 34 cases identified in 606 carcinomas. Mod Pathol. 2011;24:1069-78.

14 Kaushik S P. Current perspectivein gall bladder carcinoma. J of gastroentero and hepatology, 2001;16: 848-854

15. Lazcano-Ponce E C, Miquel J f, Muinoz N, Herrero, Ferreeio C, Wistuba, I I, Alonso de Ruiz P, et al. Epidemiology and molecular pathology of gallbladder cancer. CA Cancer J Clin, 2001; 51: 349.

16. Rai A, Mohapatra S C, Shukla H S. A review of association of dietary factors in gall bladder cancer.Ind J of Cancer, 2004; 41: 147-51.

17 Pilgrim $\mathrm{CHC}$, Usatoff V, Evans P. Consideration of anatomical structures relevant to the surgical strategy for managing gallbladder carcinoma. Eur J SurgOncol. 2009;35(11):1131-1136

18. Kalita, D., Pant, L., Singh, S., Jain, G., Kudesia, M., Gupta, K., \& Kaur, C. Impact of routine histopathological examination of gall bladder specimens on early detection of malignancy-a study of 4,115 cholecystectomy specimens. Asian Pac JCancer Prev. 2013; 14: 3315-3318. 